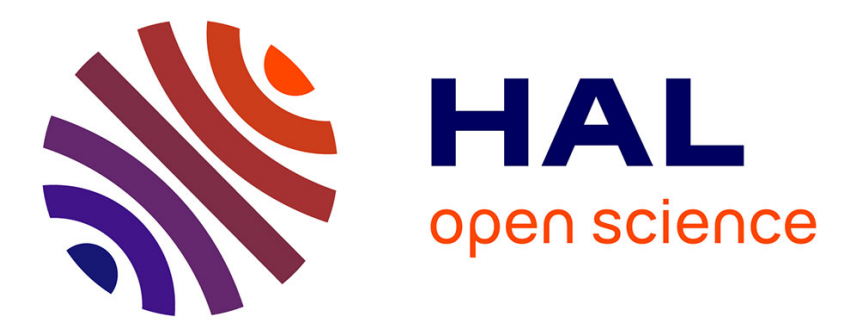

\title{
Dissolution kinetics of carbon in aluminum droplet combustion: Implications for aluminized solid propellants
}

Vincent Sarou-Kanian, Jean-Claude Rifflet, Francis Millot, Iskender Gökalp

\section{- To cite this version:}

Vincent Sarou-Kanian, Jean-Claude Rifflet, Francis Millot, Iskender Gökalp. Dissolution kinetics of carbon in aluminum droplet combustion: Implications for aluminized solid propellants. Combustion and Flame, 2007, 149 (4), pp.329-339. 10.1016/j.combustflame.2007.03.006 . hal-00429426

\section{HAL Id: hal-00429426 \\ https://hal.science/hal-00429426}

Submitted on 15 Dec 2021

HAL is a multi-disciplinary open access archive for the deposit and dissemination of scientific research documents, whether they are published or not. The documents may come from teaching and research institutions in France or abroad, or from public or private research centers.
L'archive ouverte pluridisciplinaire HAL, est destinée au dépôt et à la diffusion de documents scientifiques de niveau recherche, publiés ou non, émanant des établissements d'enseignement et de recherche français ou étrangers, des laboratoires publics ou privés. 


\title{
Dissolution kinetics of carbon in aluminum droplet
}

\section{combustion: Implications for aluminized solid propellants}

\author{
V. Sarou-Kanian ${ }^{1,2, @, ~ J . C . ~ R i f f l e t ~}{ }^{1}$, F. Millot ${ }^{1}$, and I. Gökalp ${ }^{2}$ \\ ${ }^{1}$ CNRS/CRMHT, 1 avenue de la Recherche Scientifique 45071 Orléans Cedex 2, France. \\ ${ }^{2}$ CNRS/LCSR, 1 C avenue de la Recherche Scientifique 45071 Orléans Cedex 2, France. \\ @ to whom correspondence should be addressed (sarou@cnrs-orleans.fr).
}

Full-length article

Short running title: carbon dissolution kinetics in aluminum combustion 


\begin{abstract}
An analytical model describing the kinetics of carbon dissolution in burning aluminum droplets is developed in order to simulate its effects under solid rocket motors conditions. A carbon dissolution rate $(k)$ is introduced in relation with different droplet regression laws and depending on the heterogeneous kinetics between the Al surface and the surrounding gases. The model is validated using previous experiments performed by the authors on millimeter sized Al droplets burning in several $\mathrm{CO}_{2}$ containing atmospheres at $\mathrm{P}=1 \mathrm{~atm}$. It is shown that the carbon dissolution is affected by the presence of hydrogen because of a competition between $\mathrm{CO}$ and $\mathrm{H}_{2}$ chemisorptions. The model is then applied to aluminized propellants (AP/HTPB) at high pressures $(\mathrm{P}=60 \mathrm{~atm})$ and high temperatures $(\mathrm{T}=3000 \mathrm{~K}$ and $3500 \mathrm{~K})$, and considering various burning rates and adsorption conditions. Though the accuracy of the extrapolation results needs further improvements, it is shown that the carbon dissolution process should not be neglected for the global understanding of the combustion of Al particles, particularly for agglomerates.
\end{abstract}




\section{Nomenclature}

$$
\begin{aligned}
& a_{i}=\text { dissolution parameter } \\
& b=\text { probability of } \mathrm{CO} \text { adsorption } / \mathrm{C} \text { dissolution in } \mathrm{Al} \\
& b_{0}=\text { adsorption probability } \\
& \mathrm{C}=\text { carbon concentration, } \mathrm{mol} / \mathrm{mm}^{3} \\
& \mathrm{~d}=\text { droplet diameter, } \mathrm{mm} \\
& e_{H 2}=\text { coefficient of } \mathrm{H}_{2} \text { poisoning } \\
& E_{a}=\text { activation energy, } \mathrm{eV} \\
& k=\text { carbon dissolution rate, } \mathrm{mm} / \mathrm{s} \\
& k_{P}=\text { carbon dissolution rate, } \mathrm{mm} / \mathrm{s} / \text { atm } \mathrm{CO} \\
& \mathrm{k}=\text { Boltzmann constant, } 1.381 \times 10^{-23} \mathrm{~J} / \mathrm{K} \\
& n=\text { exponent of the burning } \mathrm{d}^{n} \text { law } \\
& \mathrm{N}=\text { dissolved carbon mole number, mol } \\
& \mathrm{P}=\text { pressure, atm } \\
& \rho \quad=\quad \text { density, } \mathrm{mg} / \mathrm{mm}^{3} \\
& \mathrm{~S}=\text { droplet surface, } \mathrm{mm}^{2} \\
& \mathrm{t}=\text { time, } \mathrm{s} \\
& \mathrm{T}=\text { temperature, } \mathrm{K} \\
& \mathrm{V}=\text { droplet volume, } \mathrm{mm}^{3} \\
& \mathrm{Z}=\text { quantity of } \mathrm{CO} \text { chemisorbed on } \mathrm{Al} \text {, molecules } / \mathrm{mm}^{2} / \mathrm{s} \\
& \beta=\text { burning rate, } \mathrm{mm}^{n} / \mathrm{s} \\
& \Phi=\text { carbon flux, } \mathrm{mol} / \mathrm{mm}^{2} / \mathrm{s}
\end{aligned}
$$




\section{Subscripts and superscripts}

$\circ=$ without $\mathrm{H}_{2}$
$\mathrm{O}=$ initial
$\mathrm{Al}=$ aluminum
$\mathrm{b}=$ burning
$\mathrm{C}=$ carbon
$\mathrm{CO}=$ carbon monoxide
$\mathrm{CO} 2=$ carbon dioxide
$\mathrm{COX}=$ CO and $\mathrm{CO}_{2}$
$\mathrm{~d}=$ droplet
$\mathrm{H} 2=$ dihydrogen
$\mathrm{s}=$ surface
$\mathrm{sat}=$ saturation
$\mathrm{T}=$ total




\section{Introduction}

The dissolution of carbon in aluminum droplets burning in $\mathrm{CO}_{2}$ containing atmospheres was demonstrated in recent works [1-3]. This phenomenon is important because the amount of carbon dissolved in liquid aluminum is significant $(\approx 20 \% \mathrm{~mol} \mathrm{C}$ at $\mathrm{P}=1 \mathrm{~atm})$, and it has to be taken into account to understand the combustion processes particularly in aluminized solid propellants ( $\mathrm{P}_{\mathrm{COX}}$ up to $20 \mathrm{~atm}$ during the decomposition of AP/HTPB). Two main consequences of carbon dissolution on Al burning are identified. First, the increase of the carbon concentration in the droplet decreases aluminum vaporization $\left(\mathrm{P}_{\mathrm{Al}}\left(\mathrm{x}_{\mathrm{C}}=0.2\right) / \mathrm{P}_{\mathrm{Al}}\left(\mathrm{x}_{\mathrm{C}}=0\right) \approx 0.75\right.$ at $\left.\mathrm{T}=2600 \mathrm{~K},[4,5]\right)$ and burning rates. Second, when the carbon concentration reaches its saturation limit, the excess carbon resulting from continuous droplet regression is ejected at the surface and forms a growing solid coating which also prevents Al vaporization and gas-phase burning [2] (Figure 1:Frames 17). A new combustion regime may therefore occur when the carbon coating interacts with the oxide cap to produce an aluminum oxycarbide phase (Figure 1:Frames 8-10). In hot ambient gases, this phase can be melted which promotes direct surface reactions. The droplet is then gradually oxidized, and dissolved carbon is finally expulsed as CO from the residue which may also be a source of fragmentation [3] (Figure 1:Frames 11-15). In fact, the carbon ejection process initiates the change of the combustion regime (gas-phase to surface reactions), but it closely depends on the preliminary dissolution conditions occurring during the first burning stage.

In the present paper, a simplified analytical model is proposed in order to describe the kinetics of carbon dissolution during the combustion of aluminum droplets. Accordingly, different droplet regression laws and heterogeneous kinetics effects are considered. The model is then 
validated with the authors' experimental data, and some extrapolations for solid rocket motors conditions (particle sizes, $\mathrm{CO}_{2}$ partial pressure, and temperature) are examined and discussed.

\section{Modeling of carbon dissolution kinetics}

\subsection{Phenomenological approach}

The analysis of such a physico-chemical problem first needs the determination of the mechanisms which may control the carbon dissolution in liquid aluminum. Obviously, the carbon dissolution results from heterogeneous kinetics between liquid Al and carbonaceous gases $\left(\mathrm{CO}, \mathrm{CO}_{2}\right)$. However, homogenous processes, such as diffusion and chemical kinetics in gas phase, and diffusion of carbon in liquid $\mathrm{Al}$, have also to be discussed.

\subsubsection{Gas phase}

In a combustion regime controlled by gas phase diffusion, which is typically the case of Al burning particles for low-to-moderate pressures, $\mathrm{CO}_{2}$ is reduced by $\mathrm{Al}$ vapor in a diffusion flame clearly separated from the surface $[1-3,6,7]$. As the chemical reactions are assumed to occur with infinite kinetics, $\mathrm{CO}_{2}$ is not present in the inner zone between the particle surface and the flame front, and only $\mathrm{CO}$ is the major carbonaceous species that can diffuse and react with liquid Al. In contrast, when pressure increases above $5 \mathrm{~atm}$, it is suggested that the combustion regime is also controlled by chemical kinetics [7-9]. In such conditions, direct surface reactions are also possible between liquid $\mathrm{Al}$ and $\mathrm{CO}_{2}$. Nevertheless, based on in King's model [10] considering finite kinetics for $\mathrm{Al}$ particles $\left(\mathrm{d}_{0}<50 \mu \mathrm{m}\right)$ burning in $\mathrm{CO}_{2} / \mathrm{N}_{2}$ atmospheres, it is assumed that $\mathrm{Al}+\mathrm{CO}_{2}$ first yields to $\mathrm{AlO}+\mathrm{CO}$, and that $\mathrm{CO}$ then reacts with liquid $\mathrm{Al}$ to dissolve carbon. 


\subsubsection{Liquid phase}

Normally, the diffusion in the liquid phase is slower than in the gas phase, and it could be assumed that the diffusion of carbon in liquid aluminum is the limitating process. However, Rossi et al. [1] showed that the carbon concentration inside quenched $\mathrm{Al}$ particles $(\mathrm{d}<250 \mu \mathrm{m})$ burning in pure $\mathrm{CO}_{2}$ at $\mathrm{P}=1$ atm was fairly homogeneous. Similarly, Sarou-Kanian et al. [2] observed that a crystallized oxycarbide phase was also homogeneously dispersed in the Al matrix for millimeter sized residues in $\mathrm{H}_{2} \mathrm{O} / \mathrm{CO}_{2}$ mixtures. The carbon homogenization and the absence of concentration gradient in liquid aluminum, probably promoted by internal circulation (convection), suggest that the diffusion of carbon in the droplet is not controlled by diffusion in the liquid phase.

\subsubsection{Liquid-gas interface}

As it was previously argued for the gas phase analysis, the dissolution process first consists in the dissociative adsorption (=chemisorption) of $\mathrm{CO}$ (and not $\mathrm{CO}_{2}$ ) on the $\mathrm{Al}$ surface, and then in the diffusion of atomic $\mathrm{C}$ in the bulk. But data about the adsorption of $\mathrm{CO}$ on liquid $\mathrm{Al}$ surface do not exist. We therefore have to refer to the general theory of heterogeneous kinetics [11] and to analogous studies [12]. In a first approximation, the adsorption process is assumed to result from translational collisions of CO molecules on the Al surface. Theoretically, the quantity of $\mathrm{CO}$ chemisorbed per surface unit per second $(\mathrm{Z})$ on a mobile layer can be expressed as:

$$
\mathrm{Z}=b_{0} \frac{\mathrm{P}_{\mathrm{CO}}}{(2 \pi \mathrm{mkT})^{1 / 2}} \mathrm{e}^{-E_{a} / \mathrm{kT}}
$$

with $\mathrm{P}_{\mathrm{CO}}, \mathrm{m}, \mathrm{T}$ respectively the partial pressure, atomic mass, and temperature of $\mathrm{CO}$, and $b_{0}, E_{a}$ the probability and activation energy of adsorption of $\mathrm{CO}$ on liquid Al. For $b_{0}=1$ and $E_{a}=0$, we obtain the classical Hertz-Knudsen relation describing the maximum number of gas molecules 
striking a surface unit in a unit time. In fact, Equation 1 shows that the adsorption process depends both on the gaseous conditions near the surface $\left(\mathrm{T} \approx \mathrm{T}_{\text {droplet }}, \mathrm{P}_{\mathrm{CO}}\right)$ and on unknown adsorption parameters $\left(b_{0}, E_{a}\right)$.

Romanowski et al. [12] has investigated the chemisorption of $\mathrm{N}_{2}$ on liquid Al. Such work is interesting because $\mathrm{CO}$ and $\mathrm{N}_{2}$ are two molecules with very close chemical structures ( $\mathrm{m}=28.01$ u.m.a., 3 covalent bonds, electronic ground state ${ }^{1} \Sigma$, internuclear distance $\mathrm{N}_{2}: 1.1 \AA-$

CO: $1.13 \AA$ ). The activation energy of the $\mathrm{N}_{2}$ chemisorption on $\mathrm{Al}$ has been calculated as $E_{a}=3.0 \mathrm{eV}$. For comparison, the dissociation energies of $\mathrm{N}_{2}$ and $\mathrm{CO}$ are respectively $E_{N 2}=10 \mathrm{eV}$ and $E_{C O}=3.96 \mathrm{eV}$. This significant difference $\left(E_{N 2} / E_{C O} \approx 2.5\right)$ suggests that the activation energy of the $\mathrm{CO}$ chemisorption on $\mathrm{Al}$ may be lower than that of $\mathrm{N}_{2}$; a simple rule of proportionality such as $E_{a}(\mathrm{CO}) \approx E_{a}\left(\mathrm{~N}_{2}\right) / 2.5$ gives a realistic estimate of the maximum activation energy for $\mathrm{CO}$ $\left(E_{a} \leq 1.2 \mathrm{eV}\right)$.

\subsection{Mathematical analysis}

The present model of carbon dissolution kinetics in a burning aluminum droplet is quite simple. First, the mole number of dissolved carbon at time $t$ is considered:

$\mathrm{N}(\mathrm{t})=\mathrm{C}(\mathrm{t}) \cdot \mathrm{V}(\mathrm{t})$

with $\mathrm{C}(\mathrm{t})$ the carbon concentration (in $\mathrm{mol} \mathrm{C} / \mathrm{mm}^{3}$ ) and $\mathrm{V}(\mathrm{t})=\pi \cdot \mathrm{d}^{3}(\mathrm{t}) / 6$ the volume of the droplet at time t. Second, as the dissolution process occurs at the liquid-gas interface, $N(t)$ can also be expressed in terms of carbon flux going inside the droplet, that is:

$$
\mathrm{N}(\mathrm{t})=\int_{0}^{\mathrm{t}} \Phi\left(\mathrm{t}^{\prime}\right) \cdot \mathrm{S}\left(\mathrm{t}^{\prime}\right) \cdot \mathrm{dt^{ \prime }}
$$

with $\Phi(\mathrm{t})$ the carbon flux (in $\left.\mathrm{mol} \mathrm{C} / \mathrm{mm}^{2} / \mathrm{s}\right)$ entering $(\Phi>0)$ through the droplet surface $\mathrm{S}(\mathrm{t})=$ $\pi \cdot d^{2}(t)$ 
In order to describe this flux, the distribution of dissolved carbon in the droplet is considered homogeneous by assuming an infinitely fast diffusion of carbon in liquid aluminum (see section 2.1.2.). Accordingly, the carbon flux can be expressed as:

$$
\Phi(\mathrm{t})=k \cdot\left(\mathrm{C}_{\mathrm{sat}}-\mathrm{C}(\mathrm{t})\right)
$$

with $k$ the carbon dissolution rate (in $\mathrm{mm} / \mathrm{s}$ ), and $\mathrm{C}_{\mathrm{sat}}$ the carbon solubility (saturation limit) in liquid $\mathrm{Al}[13] . k$ may be expressed such as:

$$
k=\frac{b}{\mathrm{C}_{\mathrm{sat}}(\mathrm{T})} \frac{\mathrm{P}_{\mathrm{CO}}}{(2 \pi \mathrm{mkT})^{1 / 2}} \mathrm{e}^{-E_{a} / \mathrm{kT}}
$$

with $\mathrm{b}$ the probability of $\mathrm{CO}$ adsorption/C dissolution in liquid $\mathrm{Al}$. Note that $\mathrm{C}_{\mathrm{sat}}$ depends on the droplet temperature [4,5]. In fact, important parameters are $\mathrm{P}_{\mathrm{CO}}$ and $\mathrm{T}$. The carbon dissolution rate is directly proportional to the $\mathrm{CO}$ pressure, when the temperature dependence can be more or less effective according to the value of the activation energy. Indeed, for the case of $E_{a}=0$, the exponential terms are equal to unity, and the $\mathrm{T}^{-1 / 2}$ term does not significantly vary at high temperatures $(-20 \%$ between $2500 \mathrm{~K}$ and $3800 \mathrm{~K})$. On the contrary, if $E_{a}=1 \mathrm{eV}$, the adsorption can be multiplied by factor 4 for the same temperature range. This point will be discussed later especially for the extrapolation conditions.

From equations (2), (3), and (4), one can obtain:

$$
\mathrm{N}(\mathrm{t})=\mathrm{C}(\mathrm{t}) \cdot \mathrm{V}(\mathrm{t})=\int_{0}^{\mathrm{t}} k \cdot\left(\mathrm{C}_{\text {sat }}-\mathrm{C}\left(\mathrm{t}^{\prime}\right)\right) \cdot \mathrm{S}\left(\mathrm{t}^{\prime}\right) \cdot \mathrm{dt}^{\prime}
$$

To solve equation (9), differentiation is applied:

$$
\mathrm{dN}=\mathrm{C} \cdot \mathrm{dV}+\mathrm{V} \cdot \mathrm{dC}=k \cdot\left(\mathrm{C}_{\mathrm{sat}}-\mathrm{C}\right) \cdot \mathrm{S} \cdot \mathrm{dt}
$$

That is: 


$$
\frac{\mathrm{dC}}{\mathrm{dt}}=-\mathrm{C} \cdot\left(k \cdot \frac{\mathrm{S}}{\mathrm{V}}+\frac{1}{\mathrm{~V}} \frac{\mathrm{dV}}{\mathrm{dt}}\right)+\mathrm{C}_{\mathrm{sat}} \cdot k \cdot \frac{\mathrm{S}}{\mathrm{V}}
$$

Equation 8 is a first order differential equation with the initial condition $\mathrm{C}(\mathrm{t}=0)=0$. Its resolution depends on the expression of the droplet size evolution with time. The burning aluminum droplet size is generally considered to decrease following a " $\mathrm{d}^{n}$ law" such as $\mathrm{d}^{n}(\mathrm{t})=\mathrm{d}_{0}{ }^{n}-$ $\beta . t$ with $\mathrm{d}_{0}$ the initial droplet diameter, and $\beta$ the burning rate (in $\mathrm{mm}^{n} / \mathrm{s}$ ). $n=1,1.5$, and 2 are the most commonly used values. It has to be noted that $\beta$ corresponds to an averaged burning rate. Indeed, it should also depend on the carbon dissolution (see Introduction).

\subsubsection{Droplet size regression following a "d law": $d(t)=d_{0}-\beta t$}

$\mathrm{C}(\mathrm{t})=\mathrm{C}_{\text {sat }} \cdot \frac{1}{1-a_{1}} \cdot\left(1-\left(1-\frac{\beta}{\mathrm{d}_{0}} \cdot \mathrm{t}\right)^{3\left(\frac{1-a_{1}}{a_{1}}\right)}\right)$

with $a_{l}=\beta / 2 k$.

\subsubsection{Droplet size regression following a " $d^{2}$ law": $d^{2}(t)=d_{0}^{2}-\beta t$}

$$
\begin{aligned}
\mathrm{C}(\mathrm{t})= & \mathrm{C}_{\text {sat }} \cdot\left[1+3 a_{2} \cdot\left(1-\beta \mathrm{t} / \mathrm{d}_{0}^{2}\right)^{-1 / 2}+6 a_{2}^{2} \cdot\left(1-\beta \mathrm{t} / \mathrm{d}_{0}^{2}\right)^{-1}+6 a_{2}^{3} \cdot\left(1-\beta \mathrm{t} / \mathrm{d}_{0}^{2}\right)^{-3 / 2}\right. \\
& \left.-\left(1-\beta \mathrm{t} / \mathrm{d}_{0}^{2}\right)^{-3 / 2} \cdot \exp \left(\frac{\left(1-\beta \mathrm{t} / \mathrm{d}_{0}^{2}\right)^{1 / 2}-1}{a_{2}}\right) \cdot\left(\mathrm{d}_{0}^{3}+3 a_{2} \cdot \mathrm{d}_{0}^{2}+6 a_{2}^{2} \cdot \mathrm{d}_{0}+6 a_{2}^{3}\right)\right]
\end{aligned}
$$

with $a_{2}=\beta /\left(12 k \cdot \mathrm{d}_{0}\right)$. 


\subsubsection{Droplet size regression following a " $d^{1.5}$ law": $d^{1.5}(t)=d_{0}{ }^{1.5}-\beta t$}

$$
\begin{aligned}
\mathrm{C}(\mathrm{t})= & \mathrm{C}_{\text {sat }} \cdot\left[1+6 a_{3} \cdot\left(1-\beta \mathrm{t} / \mathrm{d}_{0}^{1.5}\right)^{-1 / 3}+30 a_{3}^{2} \cdot\left(1-\beta \mathrm{t} / \mathrm{d}_{0}^{1.5}\right)^{-2 / 3}+120 a_{3}^{3} \cdot\left(1-\beta \mathrm{t} / \mathrm{d}_{0}^{1.5}\right)^{-1}\right. \\
& +360 a_{3}^{4} \cdot\left(1-\beta \mathrm{t} / \mathrm{d}_{0}^{1.5}\right)^{-4 / 3}+720 a_{3}^{5} \cdot\left(1-\beta \mathrm{t} / \mathrm{d}_{0}^{1.5}\right)^{-5 / 3}+720 a_{3}^{6} \cdot\left(1-\beta \mathrm{t} / \mathrm{d}_{0}^{1.5} \mathrm{t}\right)^{-2} \\
& -\left(1-\beta \mathrm{t} / \mathrm{d}_{0}^{1.5}\right)^{-2} \cdot \exp \left(\frac{\left(1-\beta \mathrm{t} / \mathrm{d}_{0}^{1.5}\right)^{1 / 3}-1}{a_{3}}\right) \cdot\left(\mathrm{d}_{0}^{3}+6 a_{3} \cdot \mathrm{d}_{0}^{5 / 2}+30 a_{3}^{2} \cdot \mathrm{d}_{0}^{2}+120 a_{3}^{3} \cdot \mathrm{d}_{0}^{3 / 2}\right. \\
& \left.\left.+360 a_{3}^{4} \cdot \mathrm{d}_{0}+720 a_{3}^{5} \cdot \mathrm{d}_{0}^{1 / 2}+720 a_{3}^{6}\right)\right]
\end{aligned}
$$

with $a_{3}=\beta /\left(18 k \cdot \mathrm{d}_{0}^{0.5}\right)$.

\subsubsection{Droplet with no size regression, $\beta=0, \mathrm{dV} / \mathrm{dt}=0$}

We simply obtain:

$\mathrm{C}(\mathrm{t})=\mathrm{C}_{\mathrm{sat}} \cdot\left(1-\mathrm{e}^{-\frac{6 k}{\mathrm{~d}_{0}} \cdot \mathrm{t}}\right)$

In that case, the solubility $\mathrm{C}_{\text {sat }}$ occurs at $\mathrm{t}=\infty$.

In Equations 9-11, the parameter $a_{i}$ is introduced which compares the Al vaporization $(\beta)$ and the carbon dissolution $(k)$ rates. Note that it is nondimensional and depends as well on the initial particle diameter $\left(\mathrm{d}_{0}\right)$ for the " $\mathrm{d}^{2}$ law" and the " $\mathrm{d}^{1.5}$ law". It will be used particularly for describing the extrapolation conditions.

Figure 2 represents modeling results of carbon dissolution kinetics for an aluminum droplet of $3 \mathrm{~mm}$ initial diameter following a " $\mathrm{d}^{2}$ law" $\left(\beta=1.5 \mathrm{~mm}^{2} / \mathrm{s}\right)$, and for several values of the carbon dissolution rate $(k=0.001$ to $5 \mathrm{~mm} / \mathrm{s})$. It is shown that the saturation time $\left(\mathrm{t}_{\text {sat }}\right)$ logically increases when the carbon dissolution rate decreases; at the lowest $k$, the saturation time tends to the burning time without dissolution $\left(\mathrm{t}_{\mathrm{b}}=\mathrm{d}_{0}{ }^{2} / \beta=6 \mathrm{~s}\right)$. 


\section{Application of the model to Al burning experiments in $\mathrm{CO}_{2}$ containing atmospheres}

The estimation of the carbon dissolution parameters is based on Al burning experiments which were carried out previously for several $\mathrm{CO}_{2}$ containing atmospheres $\left(\mathrm{CO}_{2} / \mathrm{H}_{2} \mathrm{O}, \mathrm{CO}_{2} / \mathrm{H}_{2}\right.$, $\mathrm{CO}_{2} / \mathrm{N}_{2}, \mathrm{CO}_{2} / \mathrm{Ar}, \mathrm{CO}_{2} / \mathrm{He}$, and $\left.\mathrm{CO}_{2} / \mathrm{H}_{2} \mathrm{O} / \mathrm{N}_{2}\right)$ and with different $\mathrm{CO}_{2}$ concentrations $\left(\mathrm{x}_{\mathrm{CO} 2}=0.4-1\right)$, using the aerodynamic levitation technique $[2,3]$. For few experiments, the amount of dissolved carbon was quantified on the unburnt residues by using the technique of nuclear activation [14]. These data are particularly useful for low $\mathrm{CO}_{2}$ concentrations because the carbon saturation is not reached when the droplet is quenched by colliding with the walls of the levitation nozzle. In that case, the experimental burning time $\left(t_{\exp }=t_{b}\right)$ may be lower than the carbon saturation time $\left(t_{\text {sat }}\right)$. In addition, the burning experiments showing the carbon ejection at the droplet surface (Figure 1: Frame2) are also processed by assuming a carbon concentration in liquid $\mathrm{Al}$ equal to the saturation limit $\left(C\left(t_{\text {exp }}=t_{\text {sat }}\right)=C_{\text {sat }}\right)$.

Several data are needed to calculate the carbon dissolution rate. They only concern information about the $\mathrm{Al}$ droplet: the initial diameter $\left(\mathrm{d}_{0}\right)$, the burning or saturation time $\left(\mathrm{t}_{\mathrm{b}}\right.$ or $\left.t_{\text {sat }}\right)$, the final or saturation diameter $\left(\mathrm{d}\left(\mathrm{t}_{\mathrm{b}}\right)\right.$ or $\left.\mathrm{d}_{\mathrm{sat}}\right)$, the burning rate $(\beta)$, and the carbon concentration $\left(\mathrm{C}\left(\mathrm{t}_{\mathrm{b}}\right)\right.$ or $\left.\mathrm{C}_{\text {sat }}\right)$. At this step, $k$ may be estimated (Equations 12-14) without the heterogeneous kinetics effects $\left(\mathrm{T}, \mathrm{P}_{\mathrm{CO}}\right)$. In our experiments, the varying parameter is mainly the $\mathrm{CO}_{2}$ concentration. As expressed in Equation 5, the carbon dissolution rate is assumed proportional to the $\mathrm{CO}$ partial pressure, so we have introduced an intermediate parameter $k_{P}=k / \mathrm{P}_{\mathrm{CO}}$ (in mm/s/atm CO). At the surface of the burning $\mathrm{Al}$ droplet, $\mathrm{P}_{\mathrm{CO}}$ can be expressed such as: 
$\mathrm{P}_{\mathrm{CO}}=\left(\mathrm{P}_{\mathrm{T}}-\mathrm{P}_{\mathrm{Al}, \mathrm{s}}\right) \cdot \mathrm{x}_{\mathrm{CO}, \mathrm{f}}$

with $\mathrm{P}_{\mathrm{T}}$ the total pressure $(=1 \mathrm{~atm}), \mathrm{P}_{\mathrm{Al}, \mathrm{s}}$ the $\mathrm{Al}$ partial pressure at the droplet surface $(=\mathrm{f}(\mathrm{T}))$, and $\mathrm{xCO}, \mathrm{f}$ the molar fraction of $\mathrm{CO}$ in the flame assuming stoichiometric reactions. Thus, when $\mathrm{CO}_{2}$ is the only carbonaceous species in the oxidizing mixture, $\mathrm{x}_{\mathrm{CO}, \mathrm{f}}=\mathrm{x}_{\mathrm{CO} 2}$, and when the solid propellant conditions $(\mathrm{AP} / \mathrm{HTPB})$ are considered, the gaseous atmosphere contains both $\mathrm{CO}_{2}(8-$ $12 \% \mathrm{~mol})$ and $\mathrm{CO}(11-20 \% \mathrm{~mol})$, so $\mathrm{x}_{\mathrm{CO}, \mathrm{f}}=\mathrm{x}_{\mathrm{CO} 2}+\mathrm{x}_{\mathrm{CO}}$.

Figure 3 illustrates the simulated curves of the carbon dissolution kinetics for an aluminum burning droplet based on experimental data and for three regression size laws $\left(\mathrm{d}^{2}, \mathrm{~d}^{1.5}, \mathrm{~d}\right) . k_{P}$ is adjusted in order to obtain the correct experimental burning or saturation time for the correct carbon concentration. Table 1 summarizes the $k_{P}$ values estimated on 30 experiments with different $\mathrm{CO}_{2}$ concentrations. For each experiment, $k_{P}$ is quite unvarying for all the droplet regression laws. For a better analysis, the distribution of these values is shown in Figure 4. A bimodal distribution of $k_{P}$ is observed with a first narrow mode located in the range [0.06-0.10], and a second wide mode in the range [0.18-0.30]. The averaged values of both modes are $k_{P 1} \approx 0.08$ and $k_{P 2} \approx 0.25 \mathrm{~mm} / \mathrm{s} / \mathrm{atm}$ CO with acceptable relative errors $(20 \%$ on both data, Table 2).

In fact, these modes of $k_{P}$ reveal two different behaviors of the carbon dissolution kinetics which are related to the presence or the absence of hydrogenated species $\left(\mathrm{H}_{2}, \mathrm{H}_{2} \mathrm{O}\right)$ in the gaseous atmosphere. Indeed, in $\mathrm{CO}_{2} /\left(\mathrm{H}_{2} \mathrm{O}, \mathrm{H}_{2}\right)$ atmospheres, $k_{P}$ corresponds to the first mode $\left(\approx k_{P 1}\right)$, and to the second one $\left(\approx k_{P 2}\right)$ in pure $\mathrm{CO}_{2}$ or $\mathrm{CO}_{2} /\left(\mathrm{N}_{2}, \mathrm{Ar}, \mathrm{He}\right)$. Accordingly, the presence of $\mathrm{H}_{2}$ or $\mathrm{H}_{2} \mathrm{O}$ causes the carbon dissolution rate to decrease. This point was already discussed in [3] where it was showed that the carbon saturation time was longer in wet $\mathrm{CO}_{2}$ than in dry $\mathrm{CO}_{2}$ for similar droplet sizes and burning rates. First, it can be stated that it is $\mathrm{H}_{2}$ rather than $\mathrm{H}_{2} \mathrm{O}$ 
which modifies the carbon dissolution process because $\mathrm{H}_{2}$ is the major stable combustion product of $\mathrm{H}_{2} \mathrm{O}$ diffusing from the flame to the droplet surface. Furthermore, the effect of $\mathrm{H}_{2}$ results from chemical surface reactions because He which is an inert gas with close transport properties (heat and mass diffusion coefficients), does not slow down the carbon dissolution rate $\left(\approx k_{P 2}\right.$, see Table 1). It can be suggested that $\mathrm{H}_{2}$ is also chemisorbed on the Al surface, and prevents partially the $\mathrm{CO}$ adsorption. In the theory of heterogeneous kinetics, such process is called surface poisoning $[11,15]$ In our case, the poisoning by $\mathrm{H}_{2}$ on the adsorption of $\mathrm{CO}$ on liquid Al may be expressed as:

$k^{H 2}=k^{\circ} \cdot e_{H 2}$

with $k^{H 2}, k^{\circ}$ respectively the carbon dissolution rates with and without $\mathrm{H}_{2}$, and $e_{H 2}$, the parameter taking into account the hydrogen poisoning on carbon dissolution. Presently, it can be reasonably assumed that $k_{P}=k^{\circ} \approx 0.25 \mathrm{~mm} / \mathrm{s} / \mathrm{atm} \mathrm{CO}$ in dry $\mathrm{CO}_{2}$, and $k_{P} \approx 0.08 \mathrm{~mm} / \mathrm{s} / \mathrm{atm} \mathrm{CO}$ in $\mathrm{CO}_{2} /\left(\mathrm{H}_{2} \mathrm{O}\right.$ or $\mathrm{H}_{2}$ ) mixtures with $e_{H 2} \approx 1 / 3$.

\section{Extrapolations to solid rocket motors}

In the previous sections, the model of carbon dissolution kinetics have been applied to experiments of millimeter sized $\mathrm{Al}$ droplets burning in $\mathrm{CO}_{2}$ mixtures at atmospheric pressure. This allowed estimating successfully a carbon dissolution parameter $\left(k_{P}\right)$ which takes into account the $\mathrm{CO}$ pressure effect and the $\mathrm{H}_{2}$ poisoning. This section aims to describe the consequences of the carbon dissolution process on the combustion of typical Al particles in solid propellant conditions, that is for submillimeter (agglomerate) and micrometer (single) sized particles in hot ambient gases at high pressures $\left(\mathrm{P}_{\mathrm{T}} \approx 60 \mathrm{~atm}\right)$. Such extrapolations need to be 
precautious both for the input parameters $\left(\mathrm{T}, \mathrm{P}_{\mathrm{T}}, \mathrm{x}_{\mathrm{CO}, \mathrm{CO} 2}\right)$, and for the significance of the results (evaluation of the uncertainties).

\subsection{Input parameters}

The first point which must be carefully examined is the estimation of the CO pressure at the particle surface. As expressed in Equation 16, $\mathrm{P}_{\mathrm{CO}}$ is a function of the total pressure $\left(\mathrm{P}_{\mathrm{T}}\right)$, of the Al partial pressure at the particle surface $\left(\mathrm{P}_{\mathrm{Al}, \mathrm{s}}\right)$, and of the molar fraction of the carbonaceous

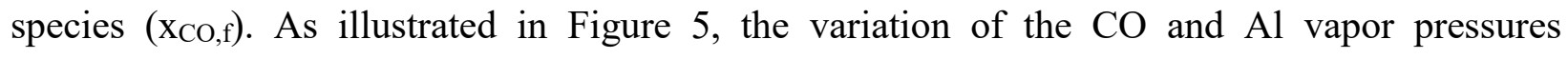
considering solid propellant conditions $\left(\mathrm{P}=60 \mathrm{~atm}, \mathrm{x}_{\mathrm{CO}, \mathrm{f}}=0.3\right)$ strongly depends on the temperature at the particle surface which is not well-known. Indeed, for classical aluminized solid propellants (AP/HTPB), the temperature of the gases in the rocket chamber at $60 \mathrm{~atm}$ was calculated as $\mathrm{T}=3400-3500 \mathrm{~K}$ (at adiabatic flame conditions, [16]). Furthermore, other works have shown that the temperature of the flame surrounding the particle varies from $\mathrm{T}=3000 \mathrm{~K}$ to $\mathrm{T}=3800 \mathrm{~K}$ for different oxidizers at $\mathrm{P}=1 \mathrm{~atm}[1,6,17,18]$. However, the influence of the pressure on the flame temperature is not clearly demonstrated because [7] indicated that $\mathrm{T}_{\text {flame }}$ was quite independent of $\mathrm{P}_{\mathrm{CO} 2}$ and was around $3200 \mathrm{~K}$, when [19] showed that it may be higher than $4300 \mathrm{~K}$ at $8.6 \mathrm{~atm}$ in $\mathrm{CO}_{2} / \mathrm{Ar}$ mixtures but with important uncertainties $(500-1400 \mathrm{~K})$. Nevertheless, further experiments performed by the latter authors [20] in similar conditions as [19], but with better optical diagnostics and analyses, measured the flame temperature in the range $3000-3200 \mathrm{~K}$ for $\mathrm{P}=8.5 \mathrm{~atm}$ in $\mathrm{CO}_{2} / \mathrm{Ar}$ and $\mathrm{CO}_{2} / \mathrm{N}_{2}$. Therefore, because of this large temperature scattering, $\mathrm{P}_{\mathrm{CO}}$ is estimated for two particle temperatures $(\mathrm{T}=3000$ and $3500 \mathrm{~K})$, with $\mathrm{P}_{\mathrm{T}}=60$ atm, and $\mathrm{x}_{\mathrm{CO}, \digamma}=0.3$, that is respectively $\mathrm{P}_{\mathrm{CO}}=17.3$ and $14.3 \mathrm{~atm}$.

The second point concerns the effect of temperature on the CO chemisorption. Previously, this was not taken into account to evaluate $k_{P}$ (except for $\left.\mathrm{P}_{\mathrm{Al}, \mathrm{s}}\right)$ because the droplet temperature 
range in our experiments was quite narrow $(2450-2600 \mathrm{~K})$. For the extrapolations at higher temperatures, this effect cannot be neglected. Nevertheless, the temperature dependence also introduces the question of the activation energy $\left(E_{a}\right)$. As it was shown in section 2.1.3., $E_{a}$ significantly modifies the effect of temperature on the adsorption process whether it is zero or not. Thus, three activation energy values will be tested $\left(E_{a}=0,0.5,1 \mathrm{eV}\right)$ corresponding to the estimated energy range [0-1.2 eV].

The third point is related to the $\mathrm{H}_{2}$ poisoning effect. As the decomposition of AP/HTPB produces significant amounts of hydrogenated species $\left(\mathrm{x}_{\mathrm{H} 2 \mathrm{O}}+\mathrm{x}_{\mathrm{H} 2} \approx 0.5\right)$, it may be reasonably assumed that this effect exists in solid propellant conditions. However, it seems difficult to estimate precisely the $\mathrm{H}_{2}$ poisoning at higher temperatures and higher pressures. As suggested previously, the poisoning corresponds to the chemisorption of $\mathrm{H}_{2}$ on the Al surface, which means that it also depends on adsorption parameters $\left(\mathrm{P}_{\mathrm{H} 2}, \mathrm{~T}, b, E_{a}\right)$. In section 3., it is shown that a low pressure of $\mathrm{H}_{2}$ leads to a decrease of the carbon dissolution parameter $k_{P}$ by a factor 3 , but there are no information about the temperature effect; also the adsorption probability and the activation energy are unknown because they are integrated in the parameter $e_{H 2}$ (Equation 17). Accordingly, the $\mathrm{H}_{2}$ poisoning effect will be taken into account for the extrapolations by keeping the same value for $e_{H 2}$.

The last point concerns the carbon solubility. The Al-C (or Al-O-C) system is monovariant which means that the carbon saturation limit in liquid $\mathrm{Al}\left(\mathrm{C}_{\mathrm{sat}}\right)$ at a fixed temperature is the same for all pressures, i.e. $\mathrm{C}_{\mathrm{sat}}=\mathrm{f}(\mathrm{T})$. [5] have extrapolated the Al-C phase diagram for pressures up to 200 bar allowing to access $C_{\text {sat }}$ at the three tested particle temperatures $\left(C_{\text {sat }}(3000 \mathrm{~K})=4.110^{-5}\right.$; $\left.\mathrm{C}_{\mathrm{sat}}(3500 \mathrm{~K})=9.610^{-5} \mathrm{~mol} \mathrm{C} / \mathrm{mm}^{3}\right)$.

\subsection{Intrinsic parameters}


At this step, the parameter $k_{p}\left(=k / \mathrm{P}_{\mathrm{CO}}\right)$ is no longer considered, and is replaced by the intrinsic parameter $b$ from Equation 5 representing the probability of $\mathrm{CO}$ adsorption/C dissolution in liquid Al. In fact, similarly to $k_{P}$ in Equation 17, $b$ also depends on the $\mathrm{H}_{2}$ poisoning and is expressed such as $b=b^{\circ} \cdot e_{H_{2}}$, with $b^{\circ}$ the probability of adsorption/dissolution without $\mathrm{H}_{2}$.

Table 3 summarizes the values of $b^{\circ}$ and $e_{H 2}$ estimated from the experimental data with a nonlinear least squared fitting (Levenberg-Marquardt algorithm, Origin 5.0 software) for the three tested activation energies, considering Equation 5, and applying the "d law" and the "d $\mathrm{d}^{2}$ law". It is observed that, as for $k_{P}, b^{\circ}$ is quite the same for both droplet regression laws (standard deviation $\approx 10 \%$ ). When the activation energy increases, the probability of adsorption/dissolution also increases, and it is interesting to note that $b^{\circ}=1$ corresponds $E_{a} \approx 1.3 \mathrm{eV}$ which is close to the qualitatively calculated maximum value (see section 2.1.3.).

With $b^{\circ}$ and $e_{H 2}$, the modeling of carbon dissolution kinetics can be then extrapolated to the propellant conditions. Table 4 and Table 5 summarize the extrapolated values of the carbon dissolution rate $(k)$ for several conditions of temperature and adsorption $\left(E_{a}\right)$ respectively considering the " $\mathrm{d}$ law" and the " $\mathrm{d}^{2}$ law". It is observed that, for the same activation energy, $k$ decreases when the temperature increases $\left(k_{M a x} / k_{M i n} \approx 3\right.$ for $0 \mathrm{eV}, \approx 2.4$ for $0.5 \mathrm{eV}, \approx 1.8$ for $1 \mathrm{eV})$. In fact, this decrease of $k\left(\sim \mathrm{Z} / \mathrm{C}_{\mathrm{sat}}\right.$, Equation 13$)$ mainly results from the increase of the carbon concentration limit $\left(\mathrm{C}_{\text {sat }}(3500 \mathrm{~K}) / \mathrm{C}_{\text {sat }}(3000 \mathrm{~K}) \approx 2.3\right)$ compared to the lower increase of the quantity of $\mathrm{CO}$ chemisorbed per surface unit per second $(\mathrm{Z}(3500 \mathrm{~K}) / \mathrm{Z}(3000 \mathrm{~K}) \approx 0.9-1.6$ for $\left.0<E_{a}<1 \mathrm{eV}\right)$.

\subsection{Saturation diameter and saturation time}

Two important data have to be extracted from such extrapolations: the saturation diameter $\left(d_{\text {sat }}\right)$ and the saturation time $\left(t_{\text {sat }}\right)$. Indeed, they characterize the particle size and the moment at 
which the gas-phase burning ends (carbon ejection) and a second combustion regime starts. To appreciate the influence of the carbon dissolution process, $d_{\text {sat }}$ and $t_{\text {sat }}$ are compared respectively to the initial particle diameter $\left(\mathrm{d}_{0}\right)$ and the burning time without dissolution $\left(\mathrm{t}_{\mathrm{b}}=\mathrm{d}_{0}{ }^{n} / \beta\right)$. Relations between $d_{s a t}, d_{0}, t_{s a t}$, and $t_{b}$ may be easily deduced as:

$$
\begin{cases}\frac{\mathrm{d}_{\text {sat }}}{\mathrm{d}_{0}}=1-\frac{\mathrm{t}_{\text {sat }}}{\mathrm{t}_{\mathrm{b}}} & \text { for a "d law" } \\ \frac{\mathrm{d}_{\text {sat }}}{\mathrm{d}_{0}}=1-\left(\frac{\mathrm{t}_{\text {sat }}}{\mathrm{t}_{\mathrm{b}}}\right)^{2} & \text { for a " } \mathrm{d}^{2} \text { law" }\end{cases}
$$

\subsection{1 "d law"}

The simple case concerns the carbon dissolution kinetics with the "d law". At carbon saturation, Equation 9 is simplified as:

$$
\left\{\begin{array}{l}
\frac{\mathrm{d}_{\mathrm{sat}}}{\mathrm{d}_{0}}=a_{1^{\frac{a_{l}}{3\left(1-a_{l}\right)}}} \\
\frac{\mathrm{t}_{\mathrm{sat}}}{\mathrm{t}_{\mathrm{b}}}=1-a_{1^{\frac{a_{l}}{3\left(-a_{l}\right)}}} \\
\mathrm{t}_{\mathrm{sat}}=\frac{\left(1-a_{1}^{\frac{a_{l}}{3\left(1-a_{l}\right)}}\right)}{\beta} \cdot \mathrm{d}_{0}
\end{array}\right.
$$

with $a_{l}=\beta / 2 k$. These expressions are interesting because they only depend on $a_{1}$, and can be simply and rapidly applied. The third expression of Equations 20 also demonstrates the linearity between $t_{\text {sat }}$ and $d_{0}$ which has been assumed in [3]. Figure 6 shows the evolution of $d_{\text {sat }} / d_{0}$ and $\mathrm{t}_{\mathrm{sat}} / \mathrm{t}_{\mathrm{b}}$ for five orders of magnitude of $a_{1}$ values $\left(a_{1}=0.01-1000\right)$, and the comparison to experimental data $\left(a_{l}=0.5-5.5\right)$.

The calculation of $a_{l}$ values requires knowing the burning rate $\beta$. A review of the literature indicates that $\beta=5-30 \mathrm{~mm} / \mathrm{s}$ for $\mathrm{d}_{0} \leq 100 \mu \mathrm{m}$ is a realistic range $[9,21,22]$. The ranges of $a_{1}$ values 
and their corresponding ranges of $d_{\text {sat }} / d_{0}$ and $t_{s a t} / t_{b}$ values are recapitulated in Table 6 (see also the dotted zone in Figure 6).

\subsection{2 "d $\mathrm{d}^{2}$ law"}

The model of carbon dissolution kinetics considering the " $\mathrm{d}^{2}$ law" is more complex than that of the "d law". However, this regression law is often used for describing the combustion of aluminum particles, and the burning rate range is defined better $\left(\beta=0.2-0.5 \mathrm{~mm}^{2} / \mathrm{s}\right)$. At the carbon saturation, Equation 10 is expressed as:

$3 a_{2} \cdot\left(\frac{\mathrm{d}_{\mathrm{sat}}}{\mathrm{d}_{0}}\right)^{2}+6 a_{2}^{2} \cdot \frac{\mathrm{d}_{\mathrm{sat}}}{\mathrm{d}_{0}}+6 a_{2}^{3}+\left(1+3 a_{2}+6 a_{2}^{2}+6 a_{2}^{3}\right) \cdot \exp \left(\frac{\mathrm{d}_{\mathrm{sat}} / \mathrm{d}_{0}-1}{a_{2}}\right)=0$

Contrary to the model with the "d law", the resolution of Equation 17 also depends on the initial particle diameter $\left(a_{2}=\beta /\left(12 k \cdot \mathrm{d}_{0}\right)\right)$. Accordingly, to extrapolate to the solid propellant conditions with this model, $\mathrm{d}_{0}$ has to be introduced. For the Ariane 5 MPS-230 propellant, [23] have proposed that the size distribution of the Al burning particles was globally composed of $2 / 3$ of initial particles $(\approx 30 \mu \mathrm{m})$ and $1 / 3$ of agglomerates $(\approx 120 \mu \mathrm{m})$. Table 7 recapitulates the extrapolated ranges of values of $a_{2}, \mathrm{~d}_{\mathrm{sat}} / \mathrm{d}_{0}$, and $\mathrm{t}_{\mathrm{sat}} / \mathrm{t}_{\mathrm{b}}$ for the burning rate range $\left[0.2-0.5 \mathrm{~mm}^{2} / \mathrm{s}\right]$ considering $\mathrm{d}_{0}=30 \mu \mathrm{m}$ and $\mathrm{d}_{0}=120 \mu \mathrm{m}$. Figure 7 represents the variation of $\mathrm{d}_{\mathrm{sat}} / \mathrm{d}_{0}$ and $\mathrm{t}_{\mathrm{sat}} / \mathrm{t}_{\mathrm{b}}$ for 5 orders of magnitude of $a_{2}(0.01-1000)$, and the comparison to experimental data $\left(a_{2}=0.1-7.33\right)$.

For both droplet regression laws, similar trends describing the evolution of $a_{i}, \mathrm{~d}_{0} / \mathrm{d}_{\text {sat }}$, and $\mathrm{t}_{\mathrm{sat}} / \mathrm{t}_{\mathrm{b}}$ are observed. The ranges of $a_{i}$ values are wide $\left(a_{\max } / a_{\min }=38\right.$ for " $\mathrm{d}$ law", $a_{\max } / a_{\min }=18$ for " $\mathrm{d}^{2}$ law") and extend to higher values when the temperature increases. The temperature effect involves a significant shifting of the ranges of $d_{\text {sat }} / d_{0}$ and $t_{\text {sat }} / t_{b}$ respectively to lower and higher 
values but with a quite unvarying width of the ranges. It can also be remarked that the ranges of $d_{\text {sat }} / d_{0}$ for the "d law" are close to those for the "d $\mathrm{d}^{2}$ law" with $\mathrm{d}_{0}=30 \mu \mathrm{m}$, while the ranges of $\mathrm{t}_{\mathrm{sat}} / \mathrm{t}_{\mathrm{b}}$ for the "d law" are close to those for the " $\mathrm{d}^{2}$ law" with $\mathrm{d}=120 \mu \mathrm{m}$. In fact, this situation indicates that the carbon ejection process considering the "d law" occurs sooner than considering the " $\mathrm{d}^{2}$ law" but for similar saturation diameters. Indeed, by fixing more precisely some of the input parameters, for example $\mathrm{d}_{0}=30 \mu \mathrm{m}$ at $\mathrm{T}=3500 \mathrm{~K}$ with $\beta_{1}=10 \mathrm{~mm} / \mathrm{s}$ or $\beta_{2}=0.3 \mathrm{~mm}^{2} / \mathrm{s}$ (same $t_{b}=3 \mathrm{~ms}$ ), we actually obtain $d_{\mathrm{sat}}=10-15 \mu \mathrm{m}$ and $\mathrm{d}_{\mathrm{sat}}=10-17 \mu \mathrm{m}$ respectively for the " $\mathrm{d}$ law" and the " $\mathrm{d}^{2}$ law" whereas $\mathrm{t}_{\mathrm{sat}}=1.5-2 \mathrm{~ms}$ for the "d law" and $\mathrm{t}_{\mathrm{sat}}=2-2.6 \mathrm{~ms}$ for the " $\mathrm{d}^{2}$ law".

\section{Summary and conclusions}

In the present work, the carbon dissolution process during the combustion of aluminum droplets has been modeled in order to understand previous experimental results and to predict its influence in the solid rocket motors conditions. The model consists to introduce a carbon dissolution rate $(k)$ in relation with different droplet regression laws $\left(\mathrm{d}, \mathrm{d}^{1.5}, \mathrm{~d}^{2}\right)$, and depending on heterogeneous kinetics between the $\mathrm{Al}$ surface and the surrounding gases (CO chemisorption). Then it has been successfully applied to our own experiments of millimeter sized $\mathrm{Al}$ droplets burning in several $\mathrm{CO}_{2}$ environments at atmospheric pressure (evaluation of the carbon dissolution parameter $k_{P}$ ), and it was shown that the carbon dissolution rate decreases in the presence of hydrogen probably because of a poisoning effect (competition between $\mathrm{H}_{2}$ and $\mathrm{CO}$ chemisorptions). Based on this validation of the model, extrapolations to submillimetric and micrometric particles in hot ambient gases at high pressures have been performed by considering numerous varying parameters (particle temperature, burning rate, activation energy, $\mathrm{H}_{2}$ poisoning). Such extrapolations allow estimating the particle size and the moment at which the carbon saturation occurs, and comparing them to the initial particle diameter and the theoretical 
gas-phase burning time. The main observation concerning the extrapolation results $\left(a_{i}, \mathrm{~d}_{\mathrm{sat}} / \mathrm{d}_{0}\right.$, $\left.t_{\mathrm{sat}} / \mathrm{t}_{\mathrm{b}}\right)$ is that the carbon dissolution process cannot be neglected in the solid rocket motors conditions. Obviously, the accuracy of the results is not completely satisfactory (wide ranges of values), there are some discrepancies between the models considering the "d law" or the " $\mathrm{d}$ law", and the variation of the particle temperature from $3000 \mathrm{~K}$ to $3500 \mathrm{~K}$ causes the shifting of the ranges of values. Nevertheless, it is shown that an $\mathrm{Al}$ particle detached from the propellant surface does not simply burn in a gas-phase regime until complete fuel depletion, but transforms into an intermediate residue of significant size and containing large amounts of carbon.

One important consequence of such mechanism concerns the particle size distribution of the oxide residues. As suggested in [3], carbon is not indefinitely trapped in the intermediate residues because surface reactions in hot ambient gases promote the oxidation of residual aluminum into alumina and the expulsion of carbon as $\mathrm{CO}$. In this second combustion regime, it may be assumed that the size of the final residue $\left(\mathrm{Al}_{2} \mathrm{O}_{3}\right)$ is close to that of the intermediate one $\left(\mathrm{Al}_{\mathrm{x}} \mathrm{O}_{\mathrm{y}} \mathrm{C}_{\mathrm{z}}\right)$. Therefore, the modeling of carbon dissolution kinetics could be an interesting insight for the understanding and the prediction of oxide particle sizing.

\section{Acknowledgments}

The authors acknowledge the support of the CNRS, the Conseil Régional Centre, and the Fonds Social Européen, Objectif 2, 2000-2006.

\section{References}

1. S. Rossi, S., E.L. Dreizin, C.K. Law, Combust. Sci. and Technol., 164 (2001) 209-237. 
2. V. Sarou-Kanian, J.C. Rifflet, F. Millot, E. Véron, T. Sauvage, I. Gökalp, Combust. Sci. and Technol., 177 (2005) 2299-2326.

3. V. Sarou-Kanian, J.C. Rifflet, F. Millot, I. Gökalp, Combust. Flame, 145 (2006) 220-230.

4. C. Qiu, R. Metselaar, J. Alloys and Compounds, 216 (1994) 55-60.

5. N.A. Gokcen, L.L. Oden, Ber. Bunsenges. Phys. Chem., $102: 9$ (1998) 1178-1180.

6. P. Bucher, R.A., Yetter, F.L. Dryer, T.P. Parr, D.M. Hanson-Parr, Proc. Combust. Inst., 27 (1996) 1899-1908.

7. B. Legrand, M. Marion, C. Chauveau, I. Gökalp, E. Shafirovich, Combust. Sci. and Technol., 165 (2001) 151-174.

8. J.C. Melcher, J.T. Brzozowski, H. Krier, R.L. Burton, AIAA paper 2000-3333 (2000).

9. J.C. Melcher, H. Krier, R.L. Burton, J. Prop. and Power, 18:3 (2002), 631-640.

10. M.K. King, Proc. Combust. Inst., 17 (1978) 1317-1328.

11. S. Gladstone, K.J. Laidler, H. Eyring, The Theory of Rate Processes, McGraw-Hill, NewYork, 1941.

12. Z. Romanowski, S. Krukowski, I. Grzegory, S. Porowski, J. Chem. Phys., 114:14 (2001) 6353-6363.

13. D. Bandyopadhyay, S.D. Singh, D. Sanyal, K.K. Singh, K.N. Singh, Chem. Eng. Journ., $94(2003)$ 79-92.

14. P. Goethals, C. Vandecasteele, J. Hoste, Analyt. Chim. Acta, 108 (1979) 367-370.

15. A. Clark, The Theory of Adsorption and Catalysis, Academic Press, New-York, 1970.

16. M. Marion, Etudes sur la combustion des particules d'aluminium sous pression, Thesis, Orléans University, France, 1996.

17. E.L. Dreizin, Combust. Flame, 105 (1996) 541. 
18. E.L. Dreizin, Combust. Flame, 117 (1999) 841.

19. N.G. Glumac, J. Servaites, H. Krier, Combust. Sci. and Technol., 172 (2001) 97-107.

20. N.G. Glumac, H. Krier, T. Bazyn, R. Eyer, Combust. Sci. and Technol., 177 (2005) 485511.

21. A. Davis, Combust. Flame, 7 (1963) 359.

22. Y. Shoshin, E.L. Dreizin, Combust. Flame,133 (2003) 275-287.

23. Y. Fabignon, O. Orlandi, J.F. Trubert, D. Lambert, J. Dupays, AIAA paper 2003-9731, (2003). 


\section{Tables}

Table 1: Experimental data and estimated dissolution rate parameters $\mathrm{k}_{\mathrm{P}}$ for the three "d laws" ( $\mathrm{n}=2,1.5$, and 1). *:carbon quantification by nuclear activation; Wet: atmosphere saturated with $\mathrm{H}_{2} \mathrm{O}$ at $\mathrm{T}=23^{\circ} \mathrm{C}$.

\begin{tabular}{|c|c|c|c|c|c|c|c|c|c|c|c|}
\hline \multirow{2}{*}{$\mathrm{x}_{\mathrm{CO} 2}$} & \multirow{2}{*}{$\mathrm{X}_{\mathrm{H} 20, \mathrm{H} 2}$} & \multirow{2}{*}{$\mathrm{X}_{\mathrm{N} 2, \mathrm{Ar}, \mathrm{He}}$} & \multirow{2}{*}{$\mathrm{d}_{0}(\mathrm{~mm})$} & \multirow{2}{*}{$\begin{array}{l}\mathrm{d}\left(\mathrm{t}_{\mathrm{b}}\right)^{*} \text { or } \mathrm{d}_{\mathrm{sat}} \\
(\mathrm{mm})\end{array}$} & \multirow{2}{*}{$\mathrm{t}_{\mathrm{b}}{ }^{*}$ or $\mathrm{t}_{\mathrm{sat}}(\mathrm{s})$} & \multirow{2}{*}{$\mathrm{T}_{\mathrm{d}}(\mathrm{K})$} & \multirow{2}{*}{$\mathrm{P}_{\mathrm{Al} . \mathrm{s}}(\mathrm{atm})$} & \multirow{2}{*}{$\mathrm{C} / \mathrm{C}_{\text {sat }}$} & \multicolumn{3}{|c|}{$k_{P}(\mathrm{~mm} / \mathrm{s} / \mathrm{atm} \mathrm{CO})$} \\
\hline & & & & & & & & & $n=2$ & $n=1.5$ & $n=1$ \\
\hline $0.4^{*}$ & 0.2 & 0.4 & 3.34 & 1.88 & 8.1 & 2450 & 0.17 & 0.89 & 0.063 & 0.065 & 0.068 \\
\hline 0.4 & 0.2 & 0.4 & 3.25 & 1.8 & 8.4 & 2450 & 0.17 & 1.00 & 0.066 & 0.069 & 0.072 \\
\hline $0.5^{*}$ & 0.5 & 0 & 3.41 & 1.56 & 5.1 & 2550 & 0.30 & 0.86 & 0.05 & 0.052 & 0.056 \\
\hline $0.5^{*}$ & Wet & 0.5 & 3.12 & 1.96 & 8.9 & 2550 & 0.30 & 0.97 & 0.082 & 0.084 & 0.087 \\
\hline 0.5 & Wet & 0.5 & 2.7 & 1.75 & 9.2 & 2550 & 0.30 & 1.00 & 0.079 & 0.081 & 0.084 \\
\hline $0.8^{*}$ & 0.2 & 0 & 2.81 & 1.62 & 4.14 & 2600 & 0.39 & 1.00 & 0.09 & 0.093 & 0.097 \\
\hline 0.8 & 0.2 & 0 & 3.17 & 1.68 & 5.25 & 2600 & 0.39 & 1.00 & 0.061 & 0.064 & 0.067 \\
\hline 0.8 & 0.2 & 0 & 3.05 & 1.74 & 4.8 & 2600 & 0.39 & 1.00 & 0.081 & 0.084 & 0.088 \\
\hline 0.8 & 0.2 & 0 & 3.26 & 1.7 & 5.36 & 2600 & 0.39 & 1.00 & 0.058 & 0.061 & 0.064 \\
\hline 0.8 & 0.2 & 0 & 3 & 1.74 & 4.6 & 2600 & 0.39 & 1.00 & 0.088 & 0.091 & 0.095 \\
\hline 0.8 & 0.2 & 0 & 3.15 & 1.88 & 4.8 & 2600 & 0.39 & 1.00 & 0.097 & 0.1 & 0.105 \\
\hline 0.8 & 0.2 & 0 & 2.9 & 1.7 & 4.3 & 2600 & 0.39 & 1.00 & 0.094 & 0.098 & 0.102 \\
\hline 0.8 & 0.2 & 0 & 3.31 & 1.86 & 4.9 & 2600 & 0.39 & 1.00 & 0.082 & 0.085 & 0.089 \\
\hline 0.8 & 0.2 & 0 & 3.42 & 1.73 & 5.85 & 2600 & 0.39 & 1.00 & 0.051 & 0.053 & 0.056 \\
\hline 0.875 & 0.125 & 0 & 3.22 & 1.97 & 4.65 & 2600 & 0.39 & 1.00 & 0.101 & 0.104 & 0.109 \\
\hline 0.875 & 0.125 & 0 & 3.5 & 2.01 & 5.45 & 2600 & 0.39 & 1.00 & 0.077 & 0.08 & 0.083 \\
\hline 1 & Wet & 0 & 3.31 & 1.78 & 6 & 2600 & 0.39 & 1.00 & 0.047 & 0.048 & 0.051 \\
\hline 1 & Wet & 0 & 3.15 & 1.93 & 5.2 & 2600 & 0.39 & 1.00 & 0.078 & 0.081 & 0.084 \\
\hline 1 & 0 & 0 & 3.4 & 2.41 & 3.5 & 2600 & 0.39 & 1.00 & 0.207 & 0.214 & 0.217 \\
\hline 1 & 0 & 0 & 3.09 & 2.33 & 3.05 & 2600 & 0.39 & 1.00 & 0.27 & 0.275 & 0.28 \\
\hline 1 & 0 & 0 & 3.15 & 2.38 & 3.35 & 2600 & 0.39 & 1.00 & 0.254 & 0.26 & 0.263 \\
\hline 1 & 0 & 0 & 4.06 & 3.18 & 4.36 & 2600 & 0.39 & 1.00 & 0.29 & 0.295 & 0.3 \\
\hline 1 & 0 & 0 & 2.5 & 1.7 & 2.7 & 2600 & 0.39 & 1.00 & 0.17 & 0.174 & 0.18 \\
\hline 1 & 0 & 0 & 2.56 & 1.87 & 2.63 & 2600 & 0.39 & 1.00 & 0.23 & 0.234 & 0.24 \\
\hline 1 & 0 & 0 & 3.2 & 2.25 & 3.86 & 2600 & 0.39 & 1.00 & 0.17 & 0.175 & 0.18 \\
\hline 0.79 & 0 & $0.21 \mathrm{He}$ & 3.28 & 2.49 & 3.84 & 2600 & 0.39 & 1.00 & 0.3 & 0.314 & 0.31 \\
\hline 0.79 & 0 & $0.21 \mathrm{He}$ & 3.5 & 2.65 & 3.89 & 2600 & 0.39 & 1.00 & 0.31 & 0.315 & 0.32 \\
\hline 0.95 & $0.05 \mathrm{H}_{2}$ & 0 & 3.35 & 2.05 & 5.2 & 2600 & 0.39 & 1.00 & 0.087 & 0.09 & 0.093 \\
\hline 0.88 & 0 & $0.12 \mathrm{Ar}$ & 3.33 & 2.52 & 4 & 2600 & 0.39 & 1.00 & 0.26 & 0.275 & 0.27 \\
\hline 0.81 & 0 & $0.19 \mathrm{~N}_{2}$ & 3.3 & 2.46 & 4.5 & 2600 & 0.39 & 1.00 & 0.23 & 0.234 & 0.24 \\
\hline
\end{tabular}


Table 2 : Averaged values of both modes of $k_{P}$.

\begin{tabular}{cccc}
\hline & $\mathrm{d}^{2}$ law & $\mathrm{d}^{1.5}$ law & $\mathrm{d}$ law \\
\hline$k_{P 1}(\mathrm{~mm} / \mathrm{s} / \mathrm{atm}$ CO $)$ & $0.075 \pm 0.017$ & $0.078 \pm 0.017$ & $0.081 \pm 0.017$ \\
$k_{P 2}(\mathrm{~mm} / \mathrm{s} / \mathrm{atm}$ CO $)$ & $0.24 \pm 0.04$ & $0.25 \pm 0.05$ & $0.255 \pm 0.05$ \\
\hline
\end{tabular}

Table 3: Estimated values of $b^{\circ}$ and $e_{H 2}$ for different activation energies, and droplet regression.

\begin{tabular}{ccccc}
\hline & \multicolumn{2}{c}{$\mathrm{d} \mathrm{law}$} & \multicolumn{2}{c}{$\mathrm{d}^{2}$ law } \\
\cline { 2 - 5 }$E_{a}(\mathrm{eV})$ & $b^{\circ}$ & $e_{H 2}$ & $b^{\circ}$ & $e_{H 2}$ \\
\hline 0 & $0.0034 \pm 0.0003$ & $0.31 \pm 0.03$ & $0.0030 \pm 0.0003$ & $0.30 \pm 0.03$ \\
0.5 & $0.031 \pm 0.003$ & $0.31 \pm 0.03$ & $0.028 \pm 0.003$ & $0.31 \pm 0.03$ \\
1 & $0.29 \pm 0.03$ & $0.32 \pm 0.03$ & $0.26 \pm 0.03$ & $0.32 \pm 0.03$ \\
1.27 & $1.0 \pm 0.1$ & $0.32 \pm 0.03$ & - & - \\
1.3 & - & - & $1.0 \pm 0.1$ & $0.32 \pm 0.03$ \\
\hline
\end{tabular}

Table 4: Extrapolated values of the carbon dissolution rate $(k)$ with a d law for different activation energies, particle temperatures, and considering the influence of the hydrogenated species.

\begin{tabular}{ccc}
\hline \multirow{2}{*}{$E_{a}(\mathrm{eV})$} & \multicolumn{2}{c}{$k(\mathrm{~mm} / \mathrm{s})$} \\
\cline { 2 - 3 } & $\mathrm{T}=3000 \mathrm{~K}$ & $\mathrm{~T}=3500 \mathrm{~K}$ \\
\hline 0 & 0.69 & 0.22 \\
0.5 & 0.93 & 0.39 \\
1 & 1.30 & 0.71 \\
1.27 & 1.41 & 0.92 \\
\hline
\end{tabular}


Table 5: Extrapolated values of the carbon dissolution rate $(k)$ with a $\mathrm{d}^{2}$ law for different activation energies, particle temperatures, and considering the influence of the hydrogenated species.

\begin{tabular}{ccc}
\hline \multirow{2}{*}{$E_{a}(\mathrm{eV})$} & \multicolumn{2}{c}{$k(\mathrm{~mm} / \mathrm{s})$} \\
\cline { 2 - 3 } & $\mathrm{T}=3000 \mathrm{~K}$ & $\mathrm{~T}=3500 \mathrm{~K}$ \\
\hline 0 & 0.60 & 0.19 \\
0.5 & 0.83 & 0.35 \\
1 & 1.14 & 0.63 \\
1.3 & 1.39 & 0.90 \\
\hline
\end{tabular}

Table 6: Extrapolated range of $a_{1}$ values for the burning rate range $\beta=5-30 \mathrm{~mm} / \mathrm{s}\left(\mathrm{d}_{0}<100 \mu \mathrm{m}\right)$ and for different particle temperatures, and their corresponding range of $\mathrm{d}_{\mathrm{sat}} / \mathrm{d}_{0}, \mathrm{t}_{\mathrm{sat}} / \mathrm{t}_{\mathrm{b}}$ values.

\begin{tabular}{cccc}
\hline $\mathrm{T}(\mathrm{K})$ & $a_{1}$ & $\mathrm{~d}_{\mathrm{sa}} / \mathrm{d}_{0}$ & $\mathrm{t}_{\mathrm{sat}} / \mathrm{t}_{\mathrm{b}}$ \\
\hline 3000 & $1.8-22$ & $0.64-0.34$ & $0.36-0.66$ \\
3500 & $2.7-69$ & $0.59-0.24$ & $0.41-0.76$ \\
\hline
\end{tabular}

Table 7: Extrapolated range of $a_{2}$ values for the burning rate range $\beta=0.2-0.5 \mathrm{~mm}^{2} / \mathrm{s}$ and for different particle temperatures and sizes, and their corresponding range of $\mathrm{d}_{\mathrm{sat}} / \mathrm{d}_{0}, \mathrm{t}_{\mathrm{sat}} / \mathrm{t}_{\mathrm{b}}$.

\begin{tabular}{ccccccc}
\hline \multirow{2}{*}{$\mathrm{T}(\mathrm{K})$} & \multicolumn{2}{c}{$a_{2}$} & \multicolumn{2}{c}{$\mathrm{d}_{\mathrm{sat}} / \mathrm{d}_{0}$} & \multicolumn{2}{c}{$\mathrm{t}_{\mathrm{sat}} / \mathrm{t}_{\mathrm{b}}$} \\
\cline { 2 - 7 } & $30 \mu \mathrm{m}$ & $120 \mu \mathrm{m}$ & $30 \mu \mathrm{m}$ & $120 \mu \mathrm{m}$ & $30 \mu \mathrm{m}$ & $120 \mu \mathrm{m}$ \\
\hline 3000 & $0.40-2.30$ & $0.10-0.58$ & $0.68-0.44$ & $0.83-0.62$ & $0.57-0.75$ & $0.41-0.62$ \\
3500 & $0.63-7.33$ & $0.16-1.83$ & $0.62-0.32$ & $0.78-0.47$ & $0.62-0.82$ & $0.47-0.73$ \\
\hline
\end{tabular}




\section{Figure captions}

Figure 1: Carbon ejection process and interaction with the oxide cap at the surface of an aluminum droplet burning in $100 \% \mathrm{CO}_{2}$.

Figure 2: Carbon dissolution kinetics for an aluminum droplet $\left(\mathrm{d}_{0}=3 \mathrm{~mm}\right)$ considering a $\mathrm{d}^{2}$ law $\left(\beta_{2}=1.5 \mathrm{~mm}^{2} / \mathrm{s}\right)$, and for different carbon dissolution rates.

Figure 3: Simulation of the carbon dissolution kinetics for an aluminum burning droplet for

three regression laws based on experimental data. $\mathrm{x}_{\mathrm{CO}_{2}}=0.8, \mathrm{~d}_{0}=3.05 \mathrm{~mm}, \mathrm{~d}_{\mathrm{sat}}=1.74 \mathrm{~mm}$, $\mathrm{t}_{\mathrm{sat}}=4.8 \mathrm{~s}, \mathrm{~T}_{\mathrm{d}}=2600 \mathrm{~K}$.

Figure 4: Distribution of $k_{P}$ (step 0.02 from 0 to 0.15 ; step 0.04 from 0.15 to 0.35 ).

Figure 5: $\mathrm{CO}$ and $\mathrm{Al}$ vapor pressures at the particle surface as a function of the temperature with $\mathrm{P}_{\mathrm{T}}=60$ atm, and $\mathrm{x}_{\mathrm{CO}, \mathrm{f}}=0.3$.

Figure 6: Variation of $\mathrm{d}_{\mathrm{sat}} / \mathrm{d}_{0}$ and $\mathrm{t}_{\mathrm{sa} a} / \mathrm{t}_{\mathrm{b}}$ as a function of parameter $a_{l}=\beta / 2 k$ for a "d law". $\bigcirc$ : experimental data. Dotted zone: extrapolation range.

Figure 7: Variation of $\mathrm{d}_{\mathrm{sa}} / \mathrm{d}_{0}$ as a function of parameter $a_{2}=\beta /\left(12 k \cdot \mathrm{d}_{0}\right)$ for different initial diameters and considering a " $\mathrm{d}^{2}$ law". $\bigcirc$ : experimental data. Extrapolation ranges: zone $\$ for $\mathrm{d}_{0}=30 \mu \mathrm{m}$, and zone $/ /$ for $\mathrm{d}_{0}=120 \mu \mathrm{m}$. 


\section{Figures}

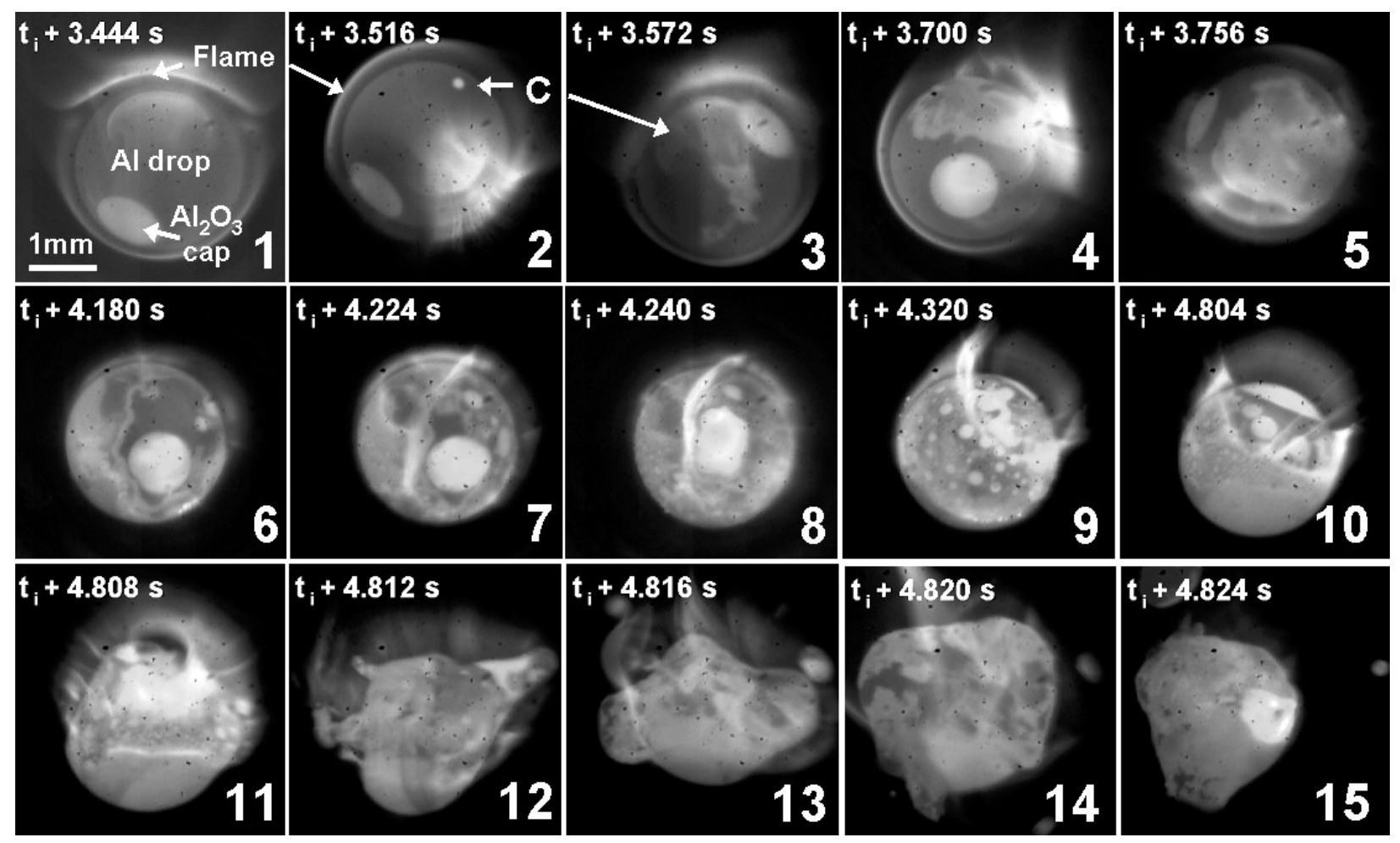

Figure 1 


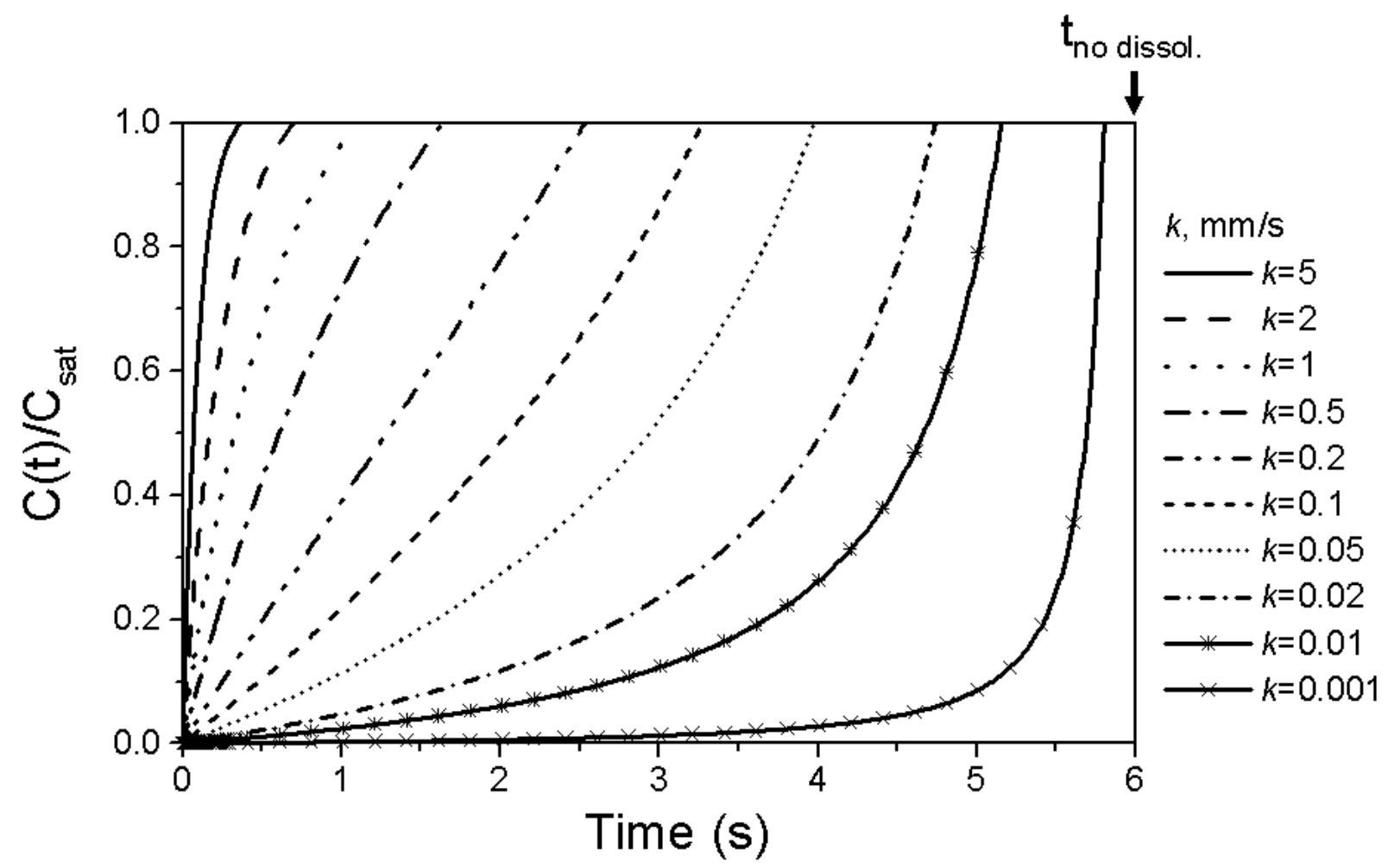

Figure 2 


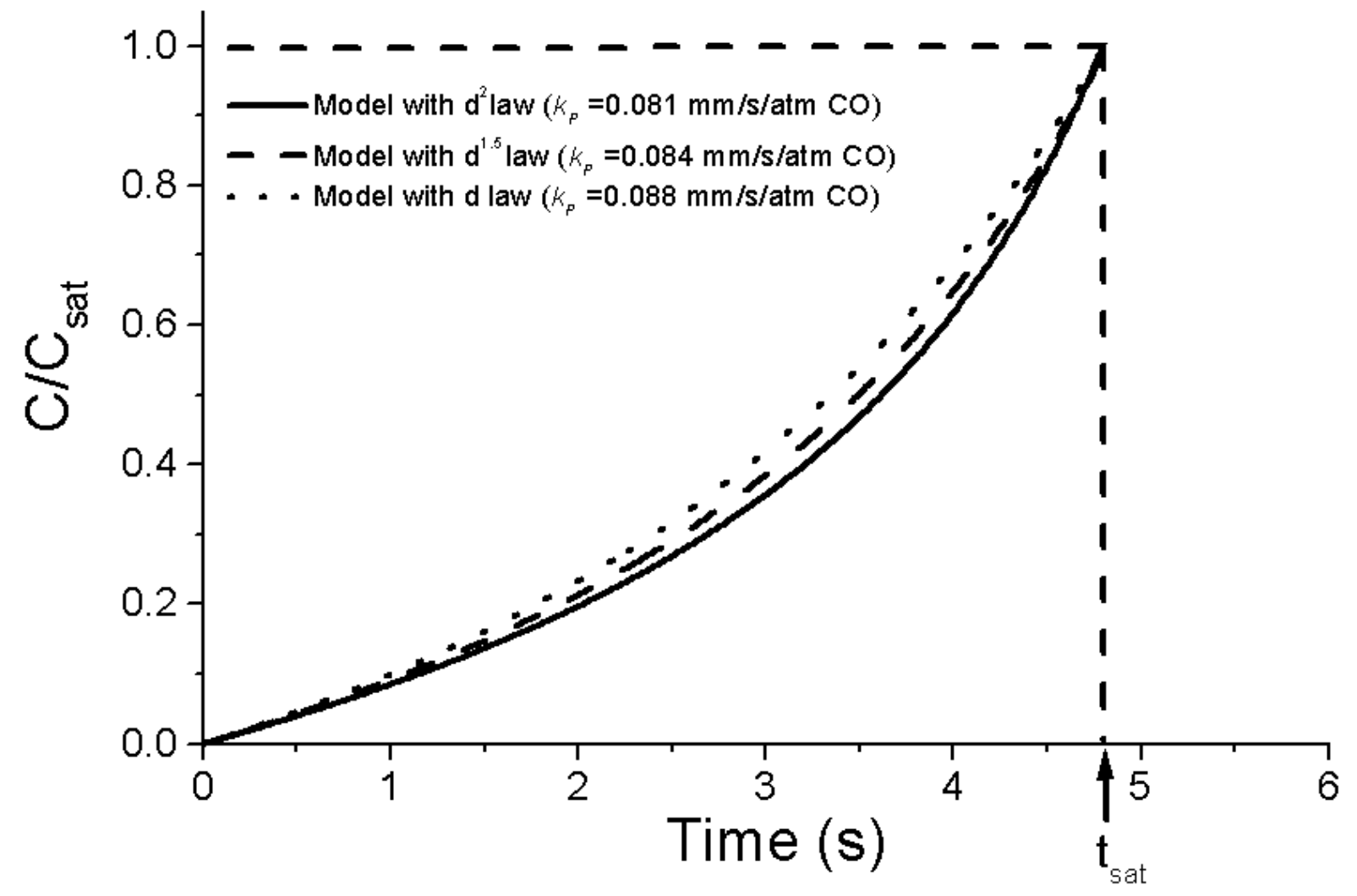

Figure 3 


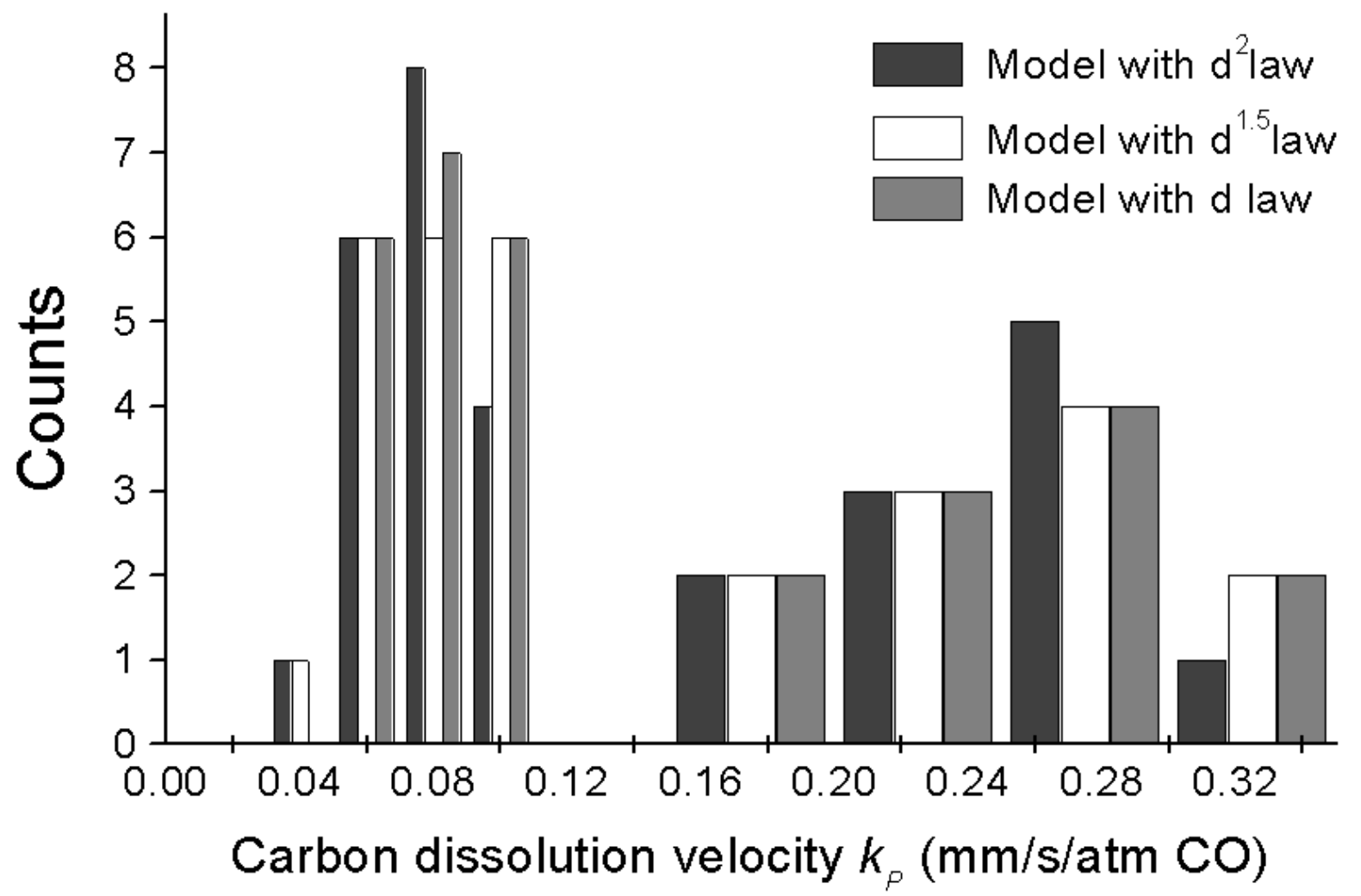

Figure 4 


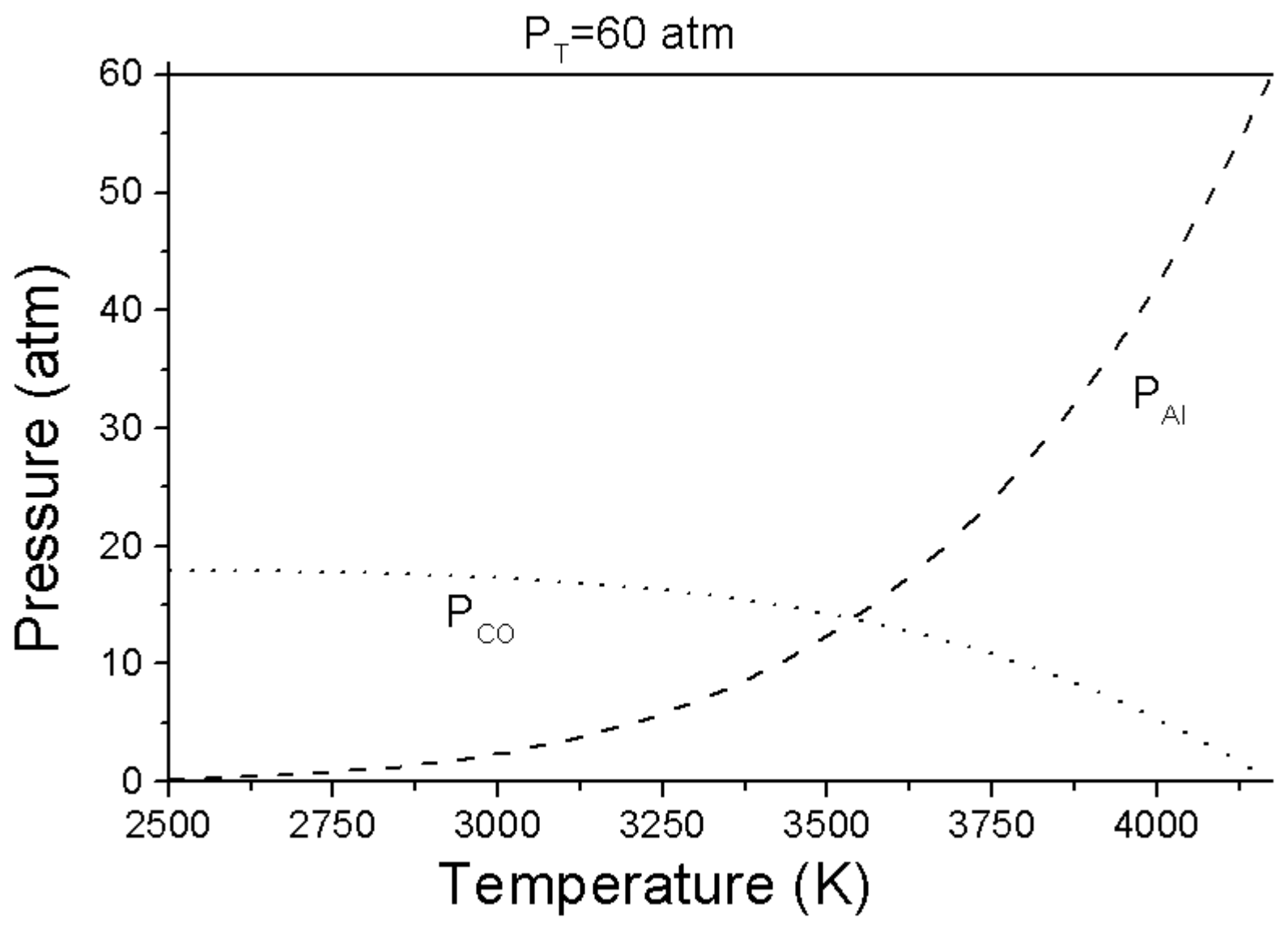

Figure 5 


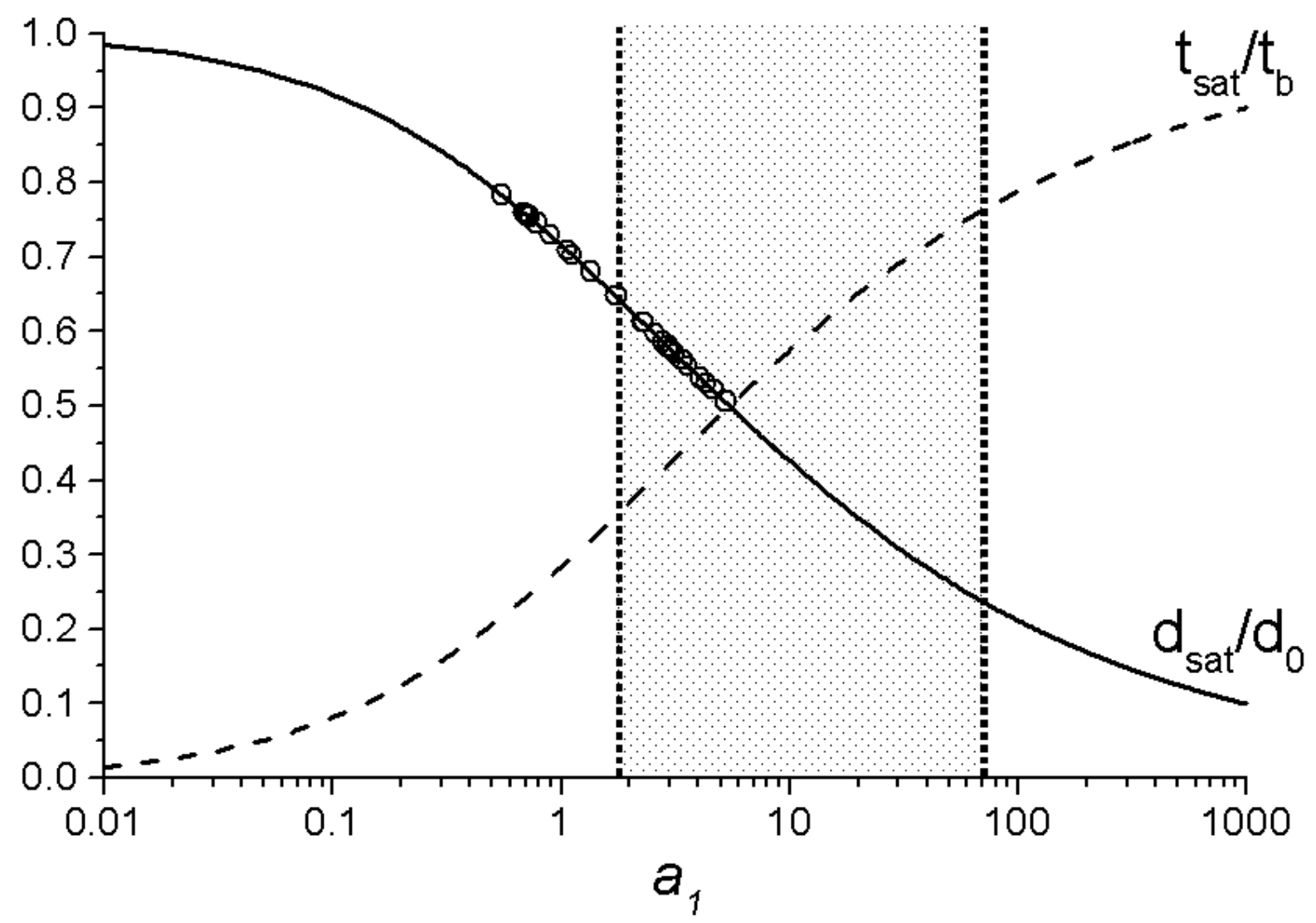

Figure 6 


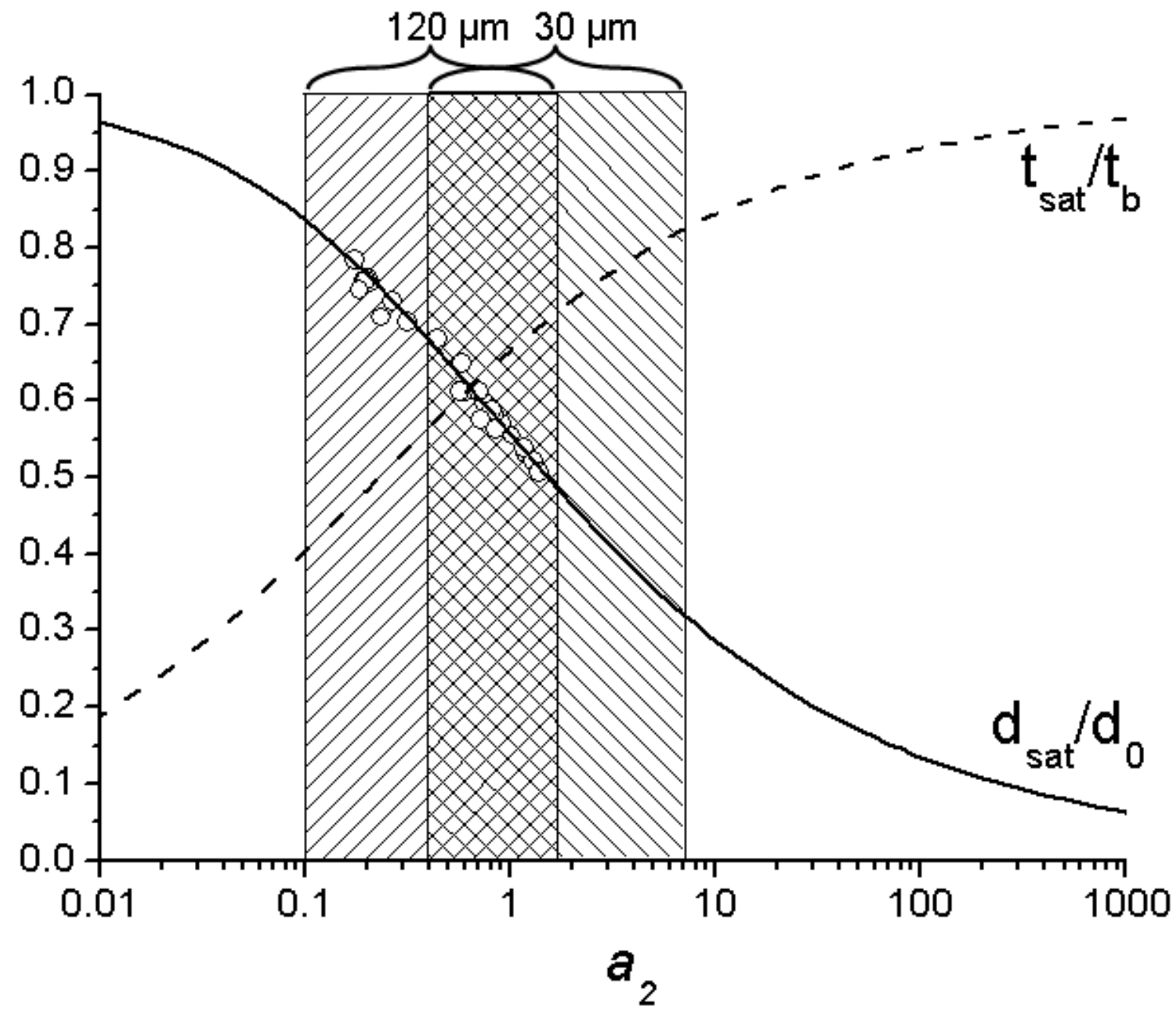

Figure 7 